\title{
The Influence of an Inquiry-based Approach on Grade Four Learners' Understanding of the Particulate Nature of Matter in the Gaseous Phase: A Case Study
}

\author{
Charles Mamombe ${ }^{{ }^{*}}$, Kgadi C Mathabathe ${ }^{1}$, Estelle Gaigher ${ }^{1}$ \\ ${ }^{1}$ University of Pretoria, SOUTH AFRICA
}

Received 7 April 2019 - Revised 9 May 2019 - Accepted 30 June 2019

\begin{abstract}
A qualitative pre-/post-test case study was conducted to explore the influence of inquiry-based education in eliciting learners' understanding of the particulate nature of matter in the gaseous phase. Two grade four classes $(n=116)$ were conveniently and purposively sampled from two farm schools in Pretoria, South Africa. Data was collected through pre-test, initial group interviews, post-test, final group interviews and field notes. The pre-intervention data indicated that the continuous, continuousanimistic and the continuous empty models of matter in the gaseous phase dominated learners' understanding in all the four classes. A considerable decrease in the continuous model was observed in the inquiry classes rather than in the lecture classes post-intervention.
\end{abstract}

Keywords: conceptual change, continuous model, inquiry-based science education, misconceptions, particulate nature of matter

\section{INTRODUCTION}

Understanding the particulate nature of matter (PNM) is important for the learning of chemistry concepts, and paves the way for the study of the structure of matter and phase changes (Novick \& Nussbaum, 1981; Stojanovska, Soptrajanov, \& Pertusevski, 2012). This topic provides a foundation for the study of diffusion, dissolution process and solution chemistry, chemical reactions and the effects of pressure, volume, temperature of gases (Stojanovska, Soptrajanov, \& Pertusevski, 2012). These topics make the backbone of chemistry, which is a more challenging section in physical science up to high school level (Department of Basic Education [DoBE], 2016). PNM is a challenging science topic, and many learners have been found to have misconceptions about the PNM in the gaseous phase (Koopman, 2017; Ozgelen, Yilmaz-Tuzun, \& Hanuscin, 2012). The science education literature describes misconceptions or alternative conceptions as incorrect ideas that are resistant to change and are often attributed to learners' prior learning and experiences with the environment (Canpolat, 2006; Driver, Guesne \& Tiberghien, 1985).

Teacher-initiated inquiry approach as used in this study is a type of inquiry method, where the teacher provides a problem, encourages learners to solve the problem, acts as a facilitator, guides and assesses learners (Llewellyn, 2011). Lessons and class activities for both educators and learners were planned following the Biological Sciences Curriculum Study (BSCS)'s 5Es model (Bybee et al., 2006). During the teacher-initiated inquiry lessons, the teacher gave probing questions to learners who worked in groups and constructed different models of their conceptions of matter in the gaseous phase. The learners engaged in discussion and asked the teacher many questions during their group activities. Each group of learners reported their understanding of matter in the gaseous phase to the class. The teacher made corrections on a few of such reports from learners.

South African learners generally perform poorly in science especially in the chemistry section (Department of Basic Education [DoBE], 2016; Mullis, Martin, \& Hooper, 2016). One possible cause of failure in chemistry at high school may be the lack of proper chemistry foundation at lower grades and misconceptions (Mullis, Martin, \& Hooper, 2016; Stojanovska, Soptrajanov, \& Pertusevski, 2012). Learners' misconceptions need to be addressed in

(C) 2020 by the authors; licensee Modestum Ltd., UK. This article is an open access article distributed under the terms and conditions of the Creative Commons Attribution License (http://creativecommons.org/licenses/by/4.0/).

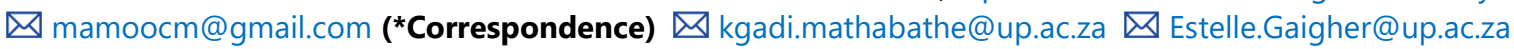




\section{Contribution of this paper to the literature}

- This study contributes to the literature on learners' conceptions of the nature of matter in the gaseous phase by showing that before learners receive formal education on the nature of matter, most learners' ideas are generally continuous models rather than particulate.

- The study provides a novel methodology of giving audience to the learners' voice and expression through drawing as an in-depth way of uncovering learners' conceptions of the nature of matter in the gaseous phase.

- The study contributes to the literature that advances the importance of effective teaching approaches such as IBE for reducing the prevalence and further development of the continuous model and promoting an increase of the particulate model in learners even at the early stages of education.

early grades, for them to understand the more advanced chemistry concepts introduced in higher grades (Areepattamannil, 2012; Stojanovska, Soptrajanov, \& Pertusevski, 2012).

The current study focused on grade four learners because PNM is first studied in grade four in the South African curriculum (Department of Basic Education, 2012). This grade seemed ideal for the current study to minimize the effects of prior exposure to the teaching of the topic using various instructional approaches on learners' understanding (Areepattamannil, 2012). Drawings were used in this study so that the young learners could express their ideas in a simpler way than for them to explain verbally. Drawings deepen learners understanding of science concepts showing their reasoning and show how much they have learned (Ainsworth, Prain, \& Tytler, 2011; Nugraha, 2018).

\section{LITERATURE REVIEW}

A study by Novick and Nussbaum (1978) laid a theoretical and methodological foundation for the current study. During that study the main models of matter, particulate (discontinuous) and continuous models were discussed. Continuous model is a view that matter exists as a continuous whole without any space or vacuum in between. In the past, the continuous model proposed by scientists such as Aristotle and Plato was the "scientifically" accepted model of matter until the 1800's when John Dalton came up with the atomic theory (Novick \& Nussbaum, 1981).

Before the atomic theory in the 1800's some scientists however, had particulate views which were not accepted by the rest of the scientific community. Examples of scientists who had particulate views of matter in the past were Lucretius in the $1^{\text {st }} \mathrm{BC}$ who proposed a particulate conception and Hero of Alexandra proposed particulate conception with the presence of a vacuum in $1 \mathrm{AD}$. Their particulate ideas did not receive recognition then, though they were correct according to the current scientific views. Recent studies on the PNM have shown that learners' initial conceptions of matter are generally continuous rather than particulate (Boz, 2006; Haidar \& Abraham, 1991; Novick \& Nussbaum, 1978). The particulate model views matter as made of particles having empty spaces / vacuum between the particles (Novick \& Nussbaum, 1978, 1981).

In the study by Novick and Nussbaum (1978), various data collection methods were used to identify learners' conceptions of matter in the topic PNM (Novick \& Nussbaum, 1985; Ozgelen, Yilmaz-Tuzun, Hanuscin, 2012). Novick and Nussbaum (1978) used a 30-minute interview procedure to investigate the extent to which about 150 learners from nine Israeli urban primary schools applied aspects of the particle model of matter in responding to eight questions based on three simple physical phenomena in the gaseous phase. Learners were asked to assume that they had magic glasses which could allow them to see air. In one of the tasks learners were shown how a vacuum pump was used to pump air out of a one-litre flask and asked to draw how air would look before and after using the vacuum pump.

Follow-up tasks examined learners' understanding about the existence of empty space between gas particles and the intrinsic motion of gas particles. $64 \%$ of the learners suggested that air is made up of particles. In the second task $78 \%$ of the learners chose diagrams of air which were drawn with particulate design. Of these learners one in six believed that particles were not evenly scattered in the container but rather confined to some part of the container. This showed the retention of some sense of continuous conception by learners. Only $35 \%$ of the sample acknowledged the existence of an empty space between gas particles. The learners suggested that between the particles there should be more particles. Some learners suggested there is dust between the particles. Others suggested there is oxygen; others suggested air, dirt, germs or unknown vapours. In one of the follow-up tasks $40 \%$ of the sample suggested that particles have intrinsic motion. There were some responses like "the particles want to rise" which showed an animistic property. However, the sample was made up of grade 8 learners who had received instruction on the topic in grade seven. 
Novick and Nussbaum, (1985) argued that an instructional approach focusing on conceptual change could stimulate and encourage the desired conceptual understanding of science topics. Instructional approaches that foster conceptual understanding have been shown to be effective in enhancing learners' understanding of foundational science concepts. The present study thus investigated whether using an inquiry-based instructional approach to teach the PNM, would assist in promoting learners' understanding or conceptual change.

Studies on IBSE have been conducted mostly at higher grades. The studies conducted with learners in higher grades found that introducing inquiry-based instruction at high school level failed to yield good results, attributing this failure to prolonged exposure of learners to rote learning (Areepattamannil, 2012). Previous studies show that grade 10 physical science teachers in South Africa appreciated that inquiry can address learner motivation and support learners' understanding of abstract science concepts. They however, did not implement inquiry learning complaining of large class sizes, the rush to complete the curriculum, and lack of resources (Ramnarain \& Hlatswayo, 2018). In another study at high school, the results showed that using inquiry learning considerably improved mastery goal-orientation as compared to the traditional direct didactic approach (Mupira \& Ramnarain, 2018). Mastery in goal-orientation is essential for improved achievement. Another study at high school revealed that the absence of practical examinations resulted in an undervaluing of inquiry-based practical work in physical sciences classrooms. And that school leadership did not support using inquiry-based learning (Tsakeni, 2018). Experiences of teachers exposed to inquiry-based learning in South Africa has revealed that most teachers appreciated the learner-centred approach and that in-service training may be of useful for such teachers ((Nico) Botha, 2016).

Existing studies have focused largely on high school level. The current study, therefore, has focused on grade four being the first primary grade where science is formally taught. The study focused on exploring the impact of inquiry-based instruction on learner conceptual understanding of matter in the gaseous phase, well before grade four learners are exposed to science instruction using rote learning.

\section{METHODOLOGY}

The present study followed a qualitative pre-test/post-test case study design with qualitative content analysis to provide more insight into learners' ideas of matter in the gaseous phase. The qualitative data constituted learner responses in the form of drawings, audio recorded explanations of learners from group interviews, and field notes. The elements of the pre-test/post-test case study methodology are evident in the comparison of conceptions of learners who received instruction following inquiry-based teaching and those who were taught using direct instruction.

\section{Sample}

Two English medium, multi-cultural, primary farm schools were purposively selected for having grade four classes and conveniently selected, based on their proximity to the researchers and to each other. The sample was made up of four grade four classes $(n=45$ in school $\mathrm{A} ; n=71$ in school B), two classes from each of the selected two schools. At each school one class was labelled as the lecture class ( $n=23$ in school A; $n=34$ in school B) and the other class was labelled the inquiry class $(n=22$ in school $\mathrm{A} ; n=37$ in school B). All classes were not aware that they would be taught differently. Both schools were composed of mainly black learners and a few mixed race learners. Data collection was done using only the scripts of learners for whom consent was given by parents or guardians. The rest of the learners whose parents had not given consent also participated in all the activities together with the rest of the class. This was done because the content of PNM in the gaseous phase is a prescribed topic in the syllabus of the learners. However, their scripts were not used in this study.

\section{Data Collection Procedure}

Ethical clearance to conduct the present study was granted by the relevant authorities prior to commencing with data collection. Initially all the four classes wrote a pre-test followed by group interviews conducted with five learners per class. Afterwards the two classes per school were simultaneously taught for two hours on the topic of PNM in the gaseous phase, using teacher-guided inquiry-based instruction (inquiry group) in one class, and direct instruction (lecture group) in the other class. Two experienced teachers who are university lecturers and well experienced in teacher education taught the two classes during the intervention. Each experienced teacher taught using the lecture method in one school and using the teacher-guided inquiry method in the other school. Soon after the intervention a post-test was administered to all classes followed by the second group interviews. 
Table 1. Pre-test item and corresponding assessment outcomes

\begin{tabular}{l|ll}
\hline Item Drawing & Description of drawing & $\begin{array}{l}\text { Aim of the question } \\
\text { Learners to demonstrate understanding of: }\end{array}$ \\
\hline $\mathbf{1}$ & Empty beaker & Air in an empty open container. \\
& & \\
&
\end{tabular}

Table 2. Example of how pre-test items were modified in the post-test

\section{Question 2 in the pre-test similar to question 3 in post- Question 3 in the post-test similar to question 2 in pre-test}

\section{test}

A glass bottle has a balloon tied at its end as shown below. The glass bottle is then heated without burning the balloon and the balloon became big. This is all shown in the diagram below.

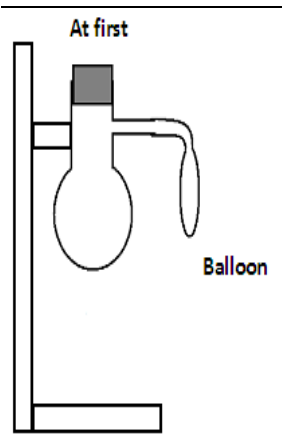

A glass bottle with water has a balloon tied at its end as shown below. The glass bottle is then heated without burning the balloon and the balloon became big. This is all shown in the diagram below.

If you had magic glasses which could see the air inside the If you had magic glasses which could see the air inside the bottle, bottle, draw the air inside the bottle before heating and after draw the air inside the bottle before heating and after heating. heating.

\section{Test Instrument}

In the current study, items used in previous studies on the same topic (Novick \& Nussbaum, 1978) were adapted in the design of the PNM Achievement Test instrument. The PNM Achievement Test instrument used during the pre-test was slightly different from the one used in the post-test, but they both tested similar concepts. To avoid language being a barrier, each of the five questions in the PNM achievement test were read to the learners, and they required the learners to respond using drawings. The learners were instructed to imagine that they were wearing 'magic' glasses which enabled them to see the sub-microscopic particles present in the test tube/beaker and had to draw air in different containers and contexts. Table 1 provides an example of one of the items in the pre- and posttest with an indication of the conception the item was designed to assess. This description was compiled for all items in the pre- and post-test to distinguish between items in the pre- and post-test and to stipulate the outcomes assessed through each item.

The post-test was contextually similar to the pre-test with minor changes and additions. The first question of the post-test was like the first question of the pre-test. The difference was that instead of an empty beaker, the posttest had an empty flask. The second question in the post-test was like the fifth question in the pre-test except that in this item the ball had less air while in the post-test the ball had a puncture. In principle both first balls had less air than the second ball. The third question in the post-test was like the second question in the pre-test (see Table 2). The slight difference was that in the pre-test the flasks were empty while in the post-test the flasks contained little water. The fourth question in the post-test was the same as question three of the pre-test. The fifth question in the post-test was the same as question four of the pre-test. The slight difference was that the first drawing of the balloon was rotated through ninety degrees. 


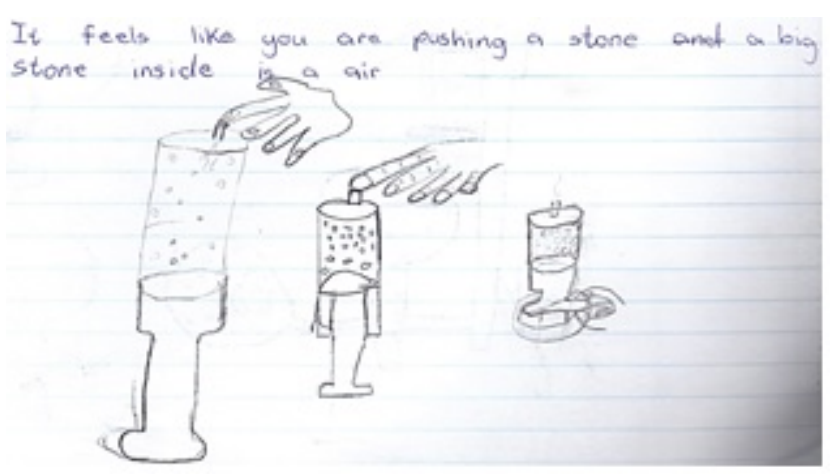

Figure 1. Drawing of compressed air drawn by a group of learners during the inquiry lesson

\section{Interview Schedule}

The schedule used for the group interviews comprised of open-ended questions that were formulated with the aim of eliciting learner conceptual understanding. The interview schedule was semi-structured to allow the researcher to probe further when necessary. The questions were dependent on the drawings the learners in the group had drawn. Each learner in a group of five was asked about their drawing in the first question before moving to the second question. As such all learners were focused on the same question standing around a table with their scripts on the table. The researcher asked all the learners one by one about their response to the same question. A question such as "What do the dots stand for?" was asked to prompt the learner to describe what he or she had drawn. A follow-up question such as "Why did you draw air using dots like this?" sought to determine the learners' justifications for their representations of air.

\section{The Teaching Intervention}

The BSCS 5Es instructional model by a group led by Bybee et al. (2006) was used as a guideline to ensure the inquiry element in the design and execution of the lesson following an inquiry-based approach. Inquiry-based instruction as conceptualized in the 5Es instructional model (Bybee et al., 2006) consists of five stages, namely the engage, exploration, explanation, elaboration and evaluation stages.

During the 'engage' stage the interest and curiosity of the learners are ignited by means of a reading, a demonstration or a question, which has the power to draw the attention of learners. In the current study the 'engage' stage was achieved by demonstrating using a syringe. The learners were given a syringe and asked, "what is inside the syringe?" and all learners responded that "There is nothing", "it's empty". Then they were asked to hold the mouth of the syringe and press in the pump. That activity gave learners the excitement that there is something inside the syringe. They were asked to discuss, thus going into the exploration stage. During the 'explore' stage, learners were provided with exploration activities which gave them concrete experiences that helped them construct concepts and develop skills so that their curiosity can be satisfied, through direct hands-on experiences. In the 'explain' stage learners used their own words to explain and listen to each other. During the 'explain' stage the teacher clarified concepts and corrected misconceptions and introduced scientific concepts. The fourth stage is the 'elaborate' stage, during which elaboration activities were used to help the learners to correct persistent misconceptions, and to discuss the applicability of learned concepts to different contexts. The fifth stage is the 'evaluate' stage where the educator evaluated learners' understanding either using the post-test and second group interview. At the same time learners also evaluated their own understanding of the concepts studied (Bybee et al., 2006).

Figure 1 is an example of one of the groups' drawing during the inquiry lesson. The group of learners said when they push the pump of the syringe with the mouth closed "It feels like you are pushing a stone. A big stone inside is the air" In the drawing the learners also drew the air before and after compression using the particulate view. It is clear that the space between particles before compression is much wider than the space between particles after compression. This shows that the group of learners had a correct idea of the particulate model during the intervention.

The lecture and the inquiry lessons had the same aim but different approaches which resulted in different activities. In the inquiry lessons learners were given a lot of materials and equipment to work with in various activities to determine answers to the questions about matter in the gaseous phase. The learners in the inquiry lessons made use of their observations and made their own representations of air in different contexts. In the lecture 


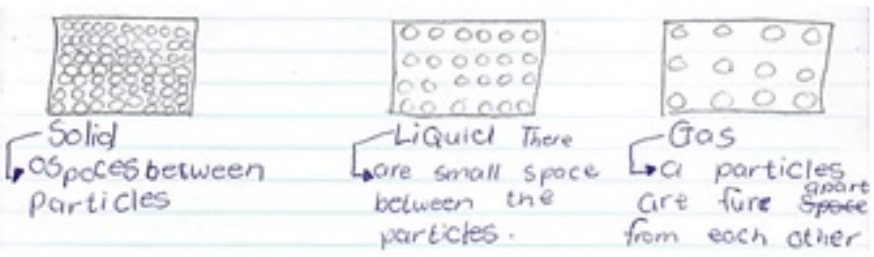

Figure 2. Drawing provided in the lecture class

Table 3. Previously identified learners' conceptions (Adapted from Novick and Nussbaum, 1981)

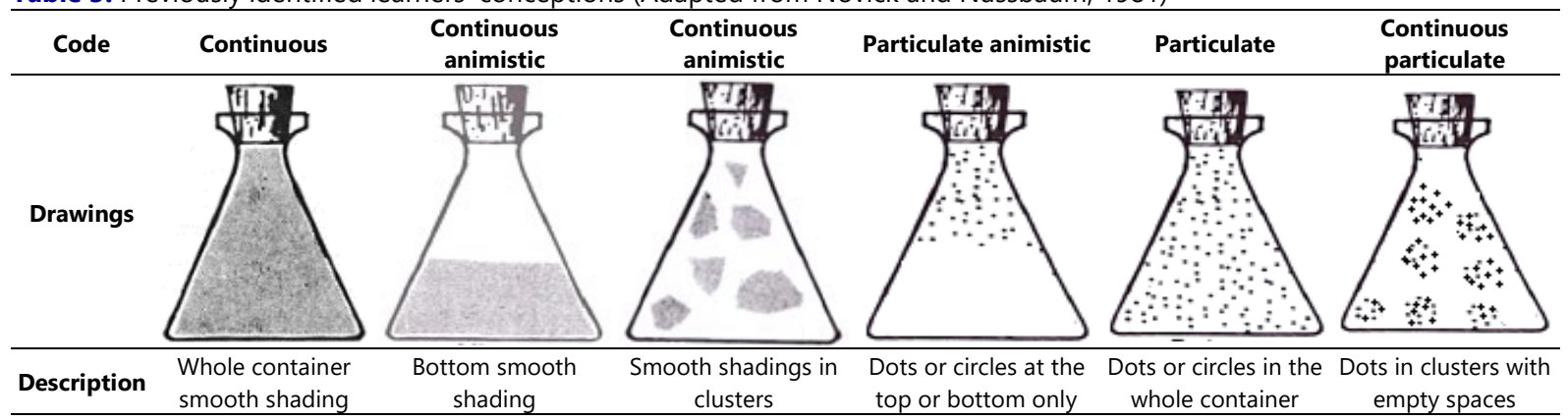

lessons learners did not do any activities. They were taught in a lecturing style and given all the notes and all the necessary drawings.

In the lecture classes the learners were exposed to lecture method which constituted mainly of the teacher telling the learners all they needed to know about the topic PNM. The learners were given clear and neat drawings which represent particles in the gaseous, liquid and solid states. They were also given drawings of air in a compressed syringe and were told that if feels hard to compress air in a syringe. They were also told that a gas takes the shape of the whole container and does not just confine at the top, bottom or centre of the container. During the lecture classes the learners wrote a lot of notes and copied a lot of drawings. Learners were instructed to paste some of the drawings in their books. The following drawing was copied by learners from the chalkboard.

\section{Data Analysis}

A coding scheme was developed based on the findings of previous research (Novick \& Nussbaum, 1981) and used during the coding process in the current research. The codes are as represented in Table 3. Learners' drawings during the pre-test and post-test, their notes during class activities and their responses during interviews were all analysed using the coding scheme developed. This study used a combination of deductive and inductive content analysis where new conceptions were allowed to emerge from the data in addition to the ones previously identified in the literature (Schreier, 2012). For assistance in data analysis we used Atlas.ti a software for qualitative data analysis. The use of Atlas.ti made the data analysis easier, faster and with clarity. Coding was done separately by two of the researchers and the results were compared. Coding disagreements were resolved through discussion. All the drawings and learners' expressions in interviews were coded and classified into relevant themes showing learners' conceptions of matter in the gaseous phase before and after instruction.

\section{RESULTS}

\section{Pre-intervention Results}

The results from the pre-test and the follow up group interviews revealed the initial understanding of the learners before instruction. The pre-intervention results indicated that both the inquiry group and the lecture group had comparable understanding to begin with. There was no noticeable distinction in the drawings made by the learners in both the lecture and the inquiry groups prior to instruction. Most learners were seemingly confused about how to go about drawing air. As such, one of the learners asked, "how is it possible to draw air which cannot be seen?" When clarified that they should imagine that they have 'magic glasses' which can allow them to see air, the learner said, "it's impossible". Some learners did not put any drawings in their diagrams. When asked "why didn't you draw anything?" their response was "air cannot be seen". Some learners however managed to make drawings which are as represented in Table 4. 
Table 4. Learners' pre-test conceptions of PNM in the gaseous phase

\begin{tabular}{|c|c|c|c|c|c|c|}
\hline & A & B & C & D & $\mathbf{E}$ & $\mathbf{F}$ \\
\hline & Continuous & Continuous animistic & Continuous empty & $\begin{array}{l}\text { Continuous } \\
\text { particulate }\end{array}$ & Particulate & Emerging ideas \\
\hline Drawings & & & & & & \\
\hline \multirow[t]{2}{*}{ Description } & $\begin{array}{c}\text { Smooth shading in the } \\
\text { whole }\end{array}$ & $\begin{array}{l}\text { Curved line shading } \\
\text { only at the bottom }\end{array}$ & $\begin{array}{l}\text { Smooth shading only } \\
\text { at the centre }\end{array}$ & $\begin{array}{c}\text { Curved shading mixed } \\
\text { with dots }\end{array}$ & $\begin{array}{c}\text { Circles to represent } \\
\text { particles }\end{array}$ & $\begin{array}{c}\text { Dots and curved line } \\
\text { drawings }\end{array}$ \\
\hline & A1 & B1 & C1 & D1 & E1 & F1 \\
\hline Description & $\begin{array}{l}\text { Curved line shading in } \\
\text { whole inner space }\end{array}$ & $\begin{array}{l}\text { Smooth shading at the } \\
\text { upper part }\end{array}$ & $\begin{array}{l}\text { Curved shading only at } \\
\text { the centre }\end{array}$ & $\begin{array}{l}\text { Smooth shading } \\
\text { mixed with dots }\end{array}$ & $\begin{array}{l}\text { Dots to represent } \\
\text { particles }\end{array}$ & $\begin{array}{l}\text { Cloud-shaped objects } \\
\text { with spaces between }\end{array}$ \\
\hline
\end{tabular}

We noticed that some learners were using smooth shading as shown in column A, and other learners used circle drawings as shown in column E just as in the previous studies. However, some learners in the current study, used curved line shadings as shown in column A1. A few of such learners were interviewed to find out what the learners meant by such drawings. When asked "What do the curved lines stand for?" the learners responded that "The curved line stand for air?". In response to a question like "What is between the curved lines you have drawn?" such learners said, "There is air between the curved lines". This gave an impression that such learners had a continuous model of matter in the gaseous phase. We therefore classified the curved lines (A1) as continuous model just like the smooth shading (A).

A few learners presented particulate views by making drawings such as represented in column E and E1. When such learners were asked "what do the circles stand for?" they responded, "the circles stand for air". And when asked "what does the space between the circles stand for?" they answered, "there is nothing" and some said, "the air is the circle". The learners who used dots had similar responses as those given by learners who used circles. Just as in the previous studies, such drawings were classified as particulate model.

Some learners held an animistic model as represented by columns B and B1 with shadings at the bottom only or at the top only. When asked "why did you only draw at the bottom? Their response was "air is resting at the bottom". When asked "why did you draw only at the top?" the response was "air wants to go to the top". Such responses gave the impression that the learners who drew those drawings believed that air behaves like animals, as such, an animistic model of air, therefore we classified their model as continuous animistic model.

Other learners had continuous empty model using smooth shading or curved lines as indicated in column $\mathrm{C}$ in Table 4. Such learners would shade at the centre or one side only. When asked "why did you draw air at the centre only?" they responded, "that's where the air is". This gave the impression that such learners even though they held a continuous model, their conception was that there was an empty space somewhere.

And yet some learners presented drawings such as represented in columns D and D1 in Table 4. Such learners drew a combination of curved lines and dots. When asked what the dots stood for, they responded "the dots represent air". And when asked what the curved lines stood for they responded, "the lines represent air". As described earlier that the curved line signified continuous model, and the dots signify particulate view, therefore a combination of the dots and curved lines showed continuous-particulate model.

And another group of learners drew the air as shown in columns F and F1. Such drawings looked different from those previously observed in other studies. When such learners were interviewed about the kind of curved lines they drew they responded, "the lines stand for air". And about the dots they responded that "the dots stand for air". These responses initially gave the impression that the learners held particulate model. However, when asked what the space between the dots represented, the responded "there is air" and some said, "there is no space". These responses gave the impression that the learners had a continuous view therefore, we could have classified their view as continuous particulate model. Nevertheless, yet others when asked about the space between the curved lines and the dots, they responded that "there is dust". Further analysis of the curved lines in these drawings showed that they did not have the same shape as the ones classified in columns A to E. We therefore classified such drawings as emerging ideas. 


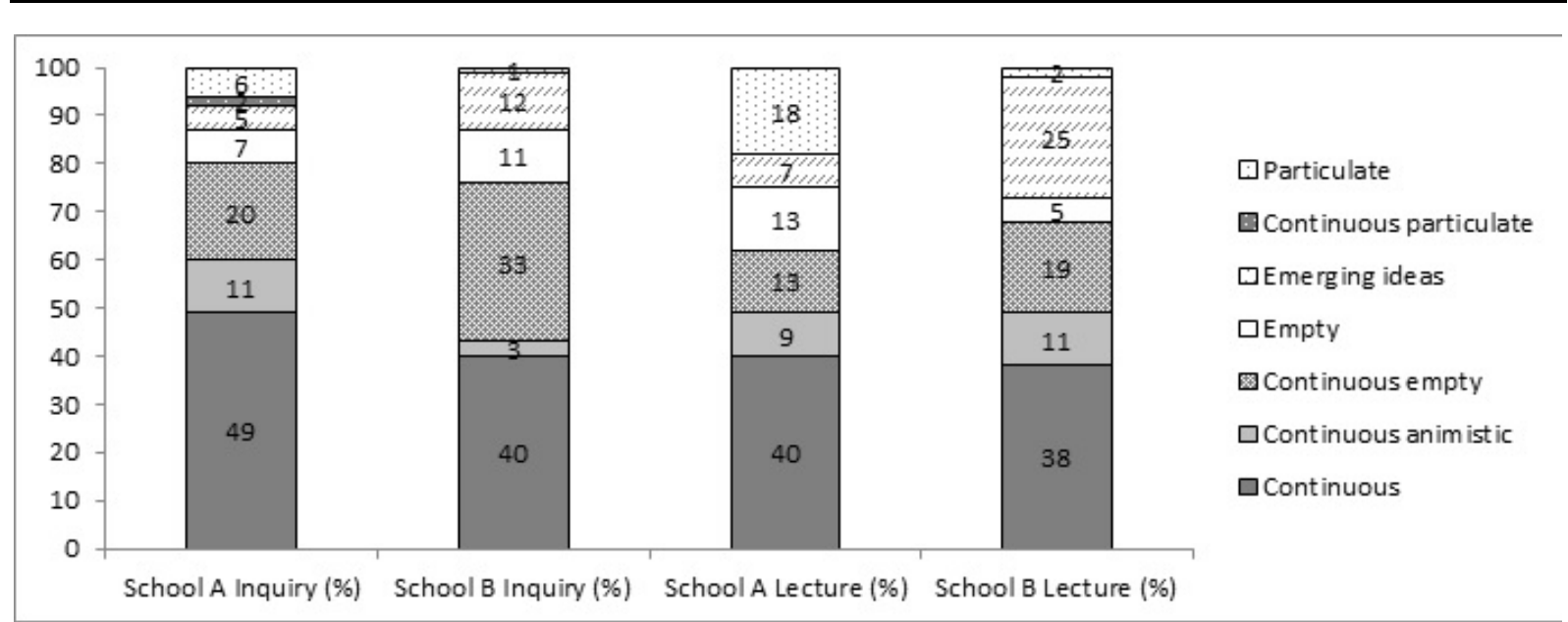

Figure 3. Overview of learners' representations of gaseous matter before teaching

Table 5. Learners' post-test conceptions of PNM in the gaseous phase

\begin{tabular}{lllll}
\hline $\begin{array}{l}\text { Conceptions } \\
\text { in the pre-test }\end{array}$ & Continuous & Continuous animistic Continuous empty & Continuous \\
Drawings
\end{tabular}

Some learners did not make any shadings in their drawings. They left the containers as empty as they were. When asked "what is inside the shape?" their response was "there is air inside". And when asked "why did you not show by drawing?" they responded, "air is inside", and some said, "how can you draw air which cannot be seen?". Such responses gave the impression that those learners had an empty model.

Figure 3 shows that the pre-test drawings and descriptions given by most of the learners in all the four classes constituted mainly of smooth shadings (A) and curved line shadings (A1) to represent continuous conception. Quite a few of the learners showed continuous animistic view (B and B1), and yet others showed continuous empty model (C and $\mathrm{C} 1$ ). Very few learners had the continuous particulate (D and D1) and the particulate model (E and E1).

\section{Post Intervention Results}

Table 5 is an overview of the learners' representations of PNM in the gaseous phase after teaching. The learners made more drawings which were clearer and easier to classify than they did in the pretest. It appears that the learners were more certain of what they wanted to draw than before teaching.

\section{Post-intervention Results (Inquiry Group)}

The results of the inquiry classes of the current study revealed a considerable improvement in the learners' drawings. There was also a great decrease in the number of learners with continuous (from $43 \%$ to $24 \%$ ) and continuous empty (from $28 \%$ to $8 \%$ ) models. Most (from $2 \%$ to $47 \%$ ) of the learners in the inquiry group used the 


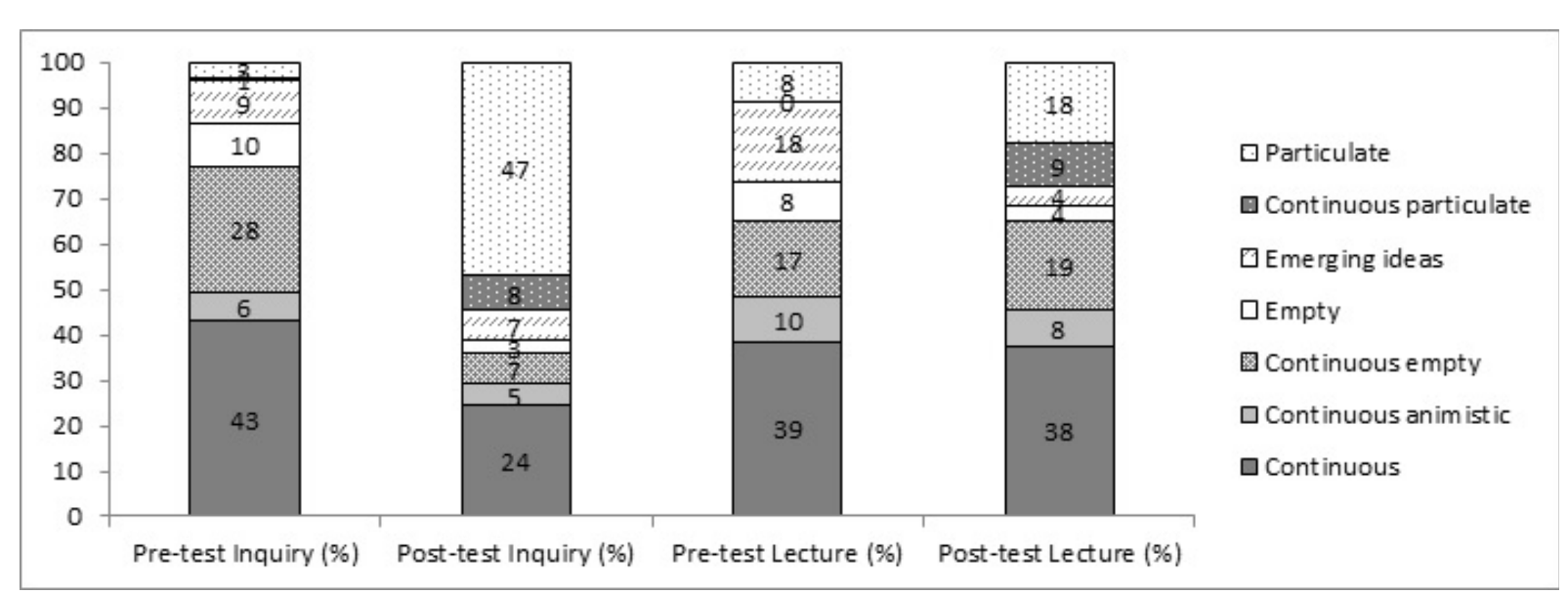

Figure 4. Comparison of learners' representations before and after the intervention

Table 6. Pre-test and post-test drawings

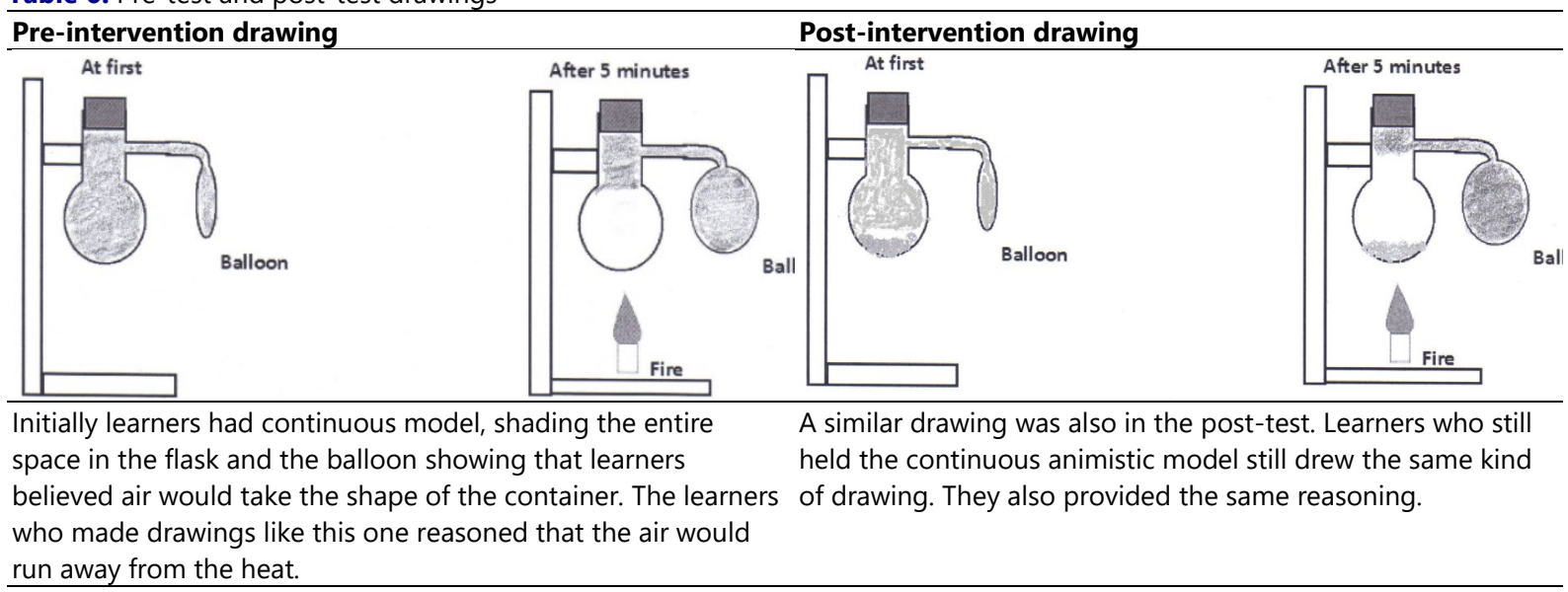

particulate model to represent PNM in the gaseous phase, followed by the continuous particulate model. There were very few emerging models in the inquiry group after the intervention.

\section{Post-intervention Results (Lecture Group)}

Similar to the inquiry group, the drawings of the learners were also clearer and easier to classify after teaching. The results of the lecture group were however, contrary to those of the inquiry group. Most learners in the lecture group showed continuous model in their post-intervention results just as they did before the intervention (39\% compared to $38 \%$ ). A large number of the learners used the continuous animistic and continuous empty models, as well as emerging models. An improvement from $8 \%$ to $18 \%$ in drawings following a particulate model was observed. Figure 4 shows that only a slight improvement was observed in the drawings of the lecture group as compared to their pre-intervention results.

In the post-test the tendency by some learners to represent air by smooth shading persisted. The shading in this case seemed deliberate and to have been drawn with care, showing that the learners had confidence in the accuracy of their drawings. Such drawings are like the ones shown in Table 6.

\section{CONCLUSIONS AND RECOMMENDATIONS}

Although great care was taken in the collection and analysis of data in this study, the interpretations of results should be handled with caution due to short treatment periods. The authors also acknowledge that there may have been other factors that played a role in enhancing learner understanding or conceptual change other than the teaching methods used. Furthermore, the sample was limited to two schools and two science education specialists as instructors; the results should therefore not be generalized. Future studies involving larger samples and using ordinary teachers as instructors should be considered. 
Most drawings identified in the current study are similar to those previously identified in similar studies carried out in developed countries (Novick \& Nussbaum, 1981). However, in the current study we observed new or emerging ideas. The interview provided an in-depth revelation about children's drawings which showed the ideas South African children have about matter. Therefore, giving an audience to learners may provide useful information about their understanding of the concepts they are studying.

Our findings suggest that teachers should take the conceptions of learners into consideration and use appropriate teaching strategies to encourage conceptual understanding of abstract science concepts. The findings in the present study seemed to suggest that although the inquiry method was more effective than the lecture method in eliciting improved particulate conception and reducing continuous conception, there was also improvement in the lecture group. Therefore, the improvement in particulate conception observed in the lecture group also suggests that well-prepared lecture lessons carry the potential of alleviating misconceptions. Teachers may need to embrace the notion of lessons following a combined approach of inquiry-based and direct instruction if they wish to teach for conceptual change. Future research may focus on the impact of longer treatment periods on learner conceptual understanding and retention of understanding of the particulate nature of matter in the gaseous phase.

\section{ACKNOWLEDGEMENTS}

The South African National Research Foundation

The grade 4 learners and their teachers as well as expert teachers who participated in the study.

\section{REFERENCES}

Ainsworth, S., Prain, V., \& Tytler, R. (2011). Drawing to Learn Science. Journal of Science Education, 1096-1097. https://doi.org/10.1126/science.1204153

Areepattamannil, S. (2012). The Effects of Inquiry-Based Science Instruction on Science Achievement and Interest in Science: Evidence from Qatar. Journal of Educational Research, 105, 134-146. https:/ / doi.org/10.1080/00220671.2010.533717

(Nico) Botha, K. R. (2016). Inquiry-based Learning: Improving South African Schools. Journal of Sociology and Social Anthropology, 7(2), 76-83. https:// doi.org/10.1080/09766634.2016.11885703

Boz, Y. (2006). Turkish Pupils' Conception of the Particulate Nature of Matter. Journal of Science Education and Technology, 15, 203-213. https:// doi.org/10.1007/s10956-006-9003-9

Bybee, R. W., Taylor, J. A., Gardner, A., Van Scotter, P., Powell, J. C., Westbrook, A., \& Landes, N. (2006). The BSCS 5E Instructional Model: Origins, Effectiveness, and Applications. Colorado Springs: Mark Dabling Boulevard.

Department of Basic Education [DoBE]. (2016). National Senior Certificate Diagnostic Report. Pretoria: Government Printing Works.

Department of Basic Education. (2012). Grades 4-6 Natural Sciences and Technology, National Curriculum Statement-CAPS. In Department of Education (Ed). Pretoria: Government Printing Works.

Driver, R., Guesne, E. \& Tiberghien, A. (1985). Children's ideas and the learning of science. In R. Guesne, \& A. Tiberghien, Children's Ideas in Science (pp. 2 - 20). Buckingham: Open University Press.

Haidar, A. H., \& Abraham, M. R. (1991). A comparison of Applied and Theoretical Knowledge of Concepts Based on the Particulate Nature of Matter. Journal of Research in Science Teaching, 28(10), 919-938. https:// doi.org/10.1002/tea.3660281004

Koopman, O. (2017). Investigating how science teachers in South Africa engage with all three levels of representation in selected chemistry topics. African Journal of Research in Mathematics, Science and Technology Education, 21(1), 15-25. https:/ / doi.org/10.1080/18117295.2016.1261546

Llewellyn, D. (2011). Differentiated Science Inquiry. Thousand Oaks, CA: Corwin Press.

Mullis, I. V., Martin, M. O., P., F., \& Hooper, M. (2016). TIMSS 2015 International Results in Mathematics. Boston College, TIMSS and PIRLS International Study Centre. Retrieved from http:/ / timssandpirls.bc.edu/timss2015/international-results

Mupira, P., \& Ramnarain, U. (2018). The effect of inquiry-based learning on achiement goal-orientation of grade 10 physical sciences learners at township schools in South Africa. Journal of Research in Science Teaching, 55, 810825. https:// doi.org/10.1002/tea.21440

Novick, S., \& Nussbaum, J. (1978). Junior High School Pupils' Understanding of Particulate Nature of Matter: An Interview Study. Science Education, 62, 273-281. https:/ / doi.org/10.1002/ sce.3730620303 
Novick, S., \& Nussbaum, J. (1981). Pupils' Understanding of the Particulate Nature of Matter: A Cross-age Study. Science Education, 64(2), 187-196. https:/ / doi.org/10.1002/sce.3730650209

Novick, S., \& Nussbaum, J. (1985). The Particulate Nature of Matter in the Gaseous Phase. In R. Guesne, \& A. Tiberghien, Children's Ideas in Science (pp. 124-142). Buckingham: Open University Press.

Nugraha, I. (2018). The use of drawing as an alternative assessment in biology teaching. Journal of Physics: Conference series, 1013-1018. https:/ / doi.org/10.1088/1742-6596/1013/1/012016

Ozgelen, S., Yilmaz-Tuzun, O., \& Hanuscin, D. L. (2012). Exploring the development of Preservice Science Educators' views on the Nature of Science in Inquiry-Based Laboratory Instruction. Journal of Research in Science Education, 43(4), 1551-1570. https: / doi.org/10.1007/s11165-012-9321-2

Ramnarain, U., \& Hlatswayo, M. (2018). Teacher beliefs and attitudes about inquiry-based learning in a rural school district in South Africa. South African Journal of Education, 38, 1-10. https://doi.org/10.15700/saje.v38n1a1431

Schreier, M. (2012). Qualitative Content Analysis in Practice. Sage Publishers.

Stojanovska, M. J., Soptrajanov, B. T., \& Pertusevski, V. M. (2012). Adressing Misconceptions about the Particulate Nature of Matter among Secondary School and High School Students in the Republic of Macedonia. Scientific Research, 3(5), 619-631. https:/ / doi.org/10.4236/ce.2012.35091

Tsakeni, M. (2018). Inquiry-based practical work in physical sciences: Equitable access and social justice issues. Issues in Educational Research, 28(1), 187-201. Retrieved from http:/ / www.iier.org.au/iier28/tsakeni.pdf

\section{http://www.ejmste.com}

